\title{
Grupos de apoio: duas experiências em cotidianos diversos
}

\author{
CÉLIA MAGALHÃES DE SOUZA* \\ SONIA REGINA POTENZA GUIMARÁES PINHEIRO**
}

\section{RESUMO}

Este artigo tem o objetivo de mostrar como as diversas açóes desenvolvidas no grupo de apoio, por meio de duas experiências apresentadas por diretoras de escolas, propiciam um movimento de construção e reconstrução conjunta, colaborativa e reflexiva, permitindo, dessa forma, um novo olhar para a formaçáo de professores em serviço, bem como para mudanças e transformaçóes das práticas em cenário escolar. Para tanto, a formação de dois grupos de apoio é apresentada, sendo uma em uma escola pública e outra em uma escola particular. Nesses grupos, são vivenciadas discussóes, sobre as ações pedagógicas desenvolvidas na escola, mediadas pela linguagem e outras ferramentas culturais construídas socialmente no ambiente escolar, que podem propiciar uma transformação nos sentidos e significados atribuídos à educaçáo escolar, para que promovam uma melhoria na qualidade de ensino, de fato e não somente de direito.

Palavras-chave: Formação de professores, Processo de ensino-aprendizagem, Prática de ensino, Qualidade do ensino.

\footnotetext{
* Mestre em Linguística Aplicada - LAEL/PUC-SP/SEE, Diretora de escola pública de ensino fundamental ciclo II e ensino médio regular (celia_1961sp@hotmail.com).

** Mestre e Doutora em Linguística Aplicada - LAEL/PUC-SP, Diretora Esportiva da Associaçáo das Escolas Particulares da Zona Sul (AESA), Diretora de escola particular de ensino fundamental e médio (sonia@escolapinheiro.com.br).
} 


\section{RESUMEN}

Este artículo pretende mostrar cómo las diferentes acciones desarrolladas en un grupo de apoyo, a través de dos experiencias presentadas por directoras de escuelas, proporcionan un movimiento de construcción y reconstrucción conjunta, colaboradora y reflexiva, lo que permite una nueva mirada para la formación de los maestros en servicio, así como para cambios y transformaciones de las prácticas en un entorno escolar. Para tal fin, se presenta la formación de dos grupos de apoyo, uno en una escuela pública y otro en una escuela privada. En esos grupos se practican discusiones sobre las acciones pedagógicas desarrolladas en la escuela, mediadas por el lenguaje y otras herramientas culturales construidas socialmente en el ambiente escolar. Acciones todas que pueden propiciar una transformación en los sentidos y significados atribuidos a la educación escolar, para promover, de hecho, una mejora en la calidad de la educación.

Palabras clave: Formación de profesores, Proceso de enseńanza-aprendizaje, Práctica de la enseñanza, Calidad de la enseñanza.

\section{ABSTRACT}

This article aims at showing how different actions, developed in group work and presented through experiences of two school directors, give way to a collective, collaborative and reflexive movement of construction and re-construction, allowing for a new look at teacher's in-service training, as well as at changing practices and transformations in schools. For that purpose, the formation of two groups is shown: one in a public school and the other in a private school. In these groups discussions were held about the instructional actions in the school, mediated by language and other socially constructed cultural tools, which can lead to transformations in the senses and meanings given to school education, so that they may eventually offer better teaching quality, not only as a right, but mainly as reality.

Keywords: Teacher training, Teaching-learning process, Teaching practice, Teaching quality. 


\section{INTRODUÇÃO}

Este artigo apresenta as experiências realizadas pelas autoras em suas respectivas escolas, sendo uma escola particular, de ensino fundamental ciclo I e II e ensino médio regular, localizada no extremo da zona sul da cidade de São Paulo, e outra pública, situada na periferia da cidade de Guarulhos, de ensino fundamental ciclo II e ensino médio regular.

As duas experiências em contextos diversos apresentam o trabalho realizado com Grupos de Apoio que segundo Daniels e Parrilla (2004) podem ser compreendidos como um espaço de discussão no qual os participantes têm oportunidades de partilharem colaborativamente as açóes propostas em reuniôes pedagógicas e/ou administrativas, visando a transformação das práticas desenvolvidas na escola e a formação continuada em serviço dos profissionais da educaçáo.

Para tanto, a experiência realizada pela Diretora Pedagógica na EP (particular) prevê reunióes mensais com a participação de professores, pais, funcionários e direçáo da escola com o objetivo de discutir os mais diversos problemas que se apresentam no cotidiano da escola, e a experiência realizada pela Diretora na BC (pública) prevê uma discussão das diversas teorias de ensino e aprendizagem com os professores e professores coordenadores pedagógicos nas reunióes semanais de horário de trabalho pedagógico coletivo, doravante HTPC, com o objetivo de construção de conhecimento que permita aprimorar o trabalho pedagógico em sala de aula.

Ambos os estudos tiveram como suporte teórico os seguintes autores: Vygotsky (1930/2002), entendendo que o conceito de mediaçáo é central nos Grupos de Apoio; Engeström (1999), que apresenta a Teoria da Atividade, explicando as açóes dos homens a partir de suas necessidades e consequentes objetivos e Daniels e Parrilla (2004) que falam de suas experiências com Grupos de Apoio na Inglaterra e na Espanha.

As experiências apresentadas se utilizam do viés metodológico conhecido como Pesquisa Crítica de Colaboração (Magalhães et al., 2006) que lhes forneceu meios para investigar não somente a constituição dos sujeitos dentro dos Grupos de Apoio, mas também a sua forma de participaçáo, as transformações e significados que foram construídos no decorrer das pesquisas.

Este artigo está dividido em três partes: 1) princípios teóricos; 2) apresentação das experiências; 3) consideraçóes finais. 


\section{PRINCÍPIOS TEÓRICOS}

Para que possamos compreender a formação de um Grupo de Apoio e as açóes que dele podem derivar, buscamos principalmente os estudos teóricos de Vygotsky (1930/2002), que ressaltam a reflexáo crítica sobre o processo de ensino-aprendizagem, visando a melhoria da qualidade da educaçáo.

Estes estudos centram-se principalmente no conceito de zona de desenvolvimento proximal, no qual Vygotsky argumenta que é por meio da linguagem e das relações sociais e formas colaborativas de comportamento, desenvolvidas nas comunidades de prática nas quais o aluno está inserido, que acontecem as relaçōes entre aprendizado e desenvolvimento. Cada assunto tratado na escola tem a sua própria relação específica com o curso do desenvolvimento do aluno, relaçáo essa que varia à medida que ele vai se apropriando do conhecimento. Vygotsky expóe que para descobrir as relaçóes reais entre o processo de desenvolvimento e a capacidade de aprendizado, devemos determinar dois níveis de desenvolvimento:

o nível de desenvolvimento real, isto é, o nível de desenvolvimento das funçôes mentais da criança que se estabeleceram como resultado de certos ciclos de desenvolvimento já completados e o nível de desenvolvimento potencial, que se refere àquelas funçôes que ainda não amadureceram, mas que estão em processo de maturação, funçōes que amadureceráo, mas que estão presentemente em estado embrionário. (Vygotsky, 1930/2002, p. 111)

Nessa perspectiva, é possível compreender a importância das relaçóes entre os sujeitos participantes do processo ensino-aprendizagem que, a partir de suas experiências individuais, constroem conhecimentos coletivos, de forma partilhada, propiciando transformações nas práticas escolares.

Em consonância com o exposto, os estudos teóricos da Teoria da Atividade, desenvolvidos por Engeström (1999), definem a atividade como uma formaçáo coletiva e sistêmica, com uma estrutura mediacional complexa.

Um sistema de atividade produz açóes e é realizado por meio de açôes, porém nâo se reduz a elas. Os sistemas de atividade se desdobram por longos períodos de tempo sócio-histórico, muitas vezes assumindo a forma de instituiçóes e organizaçōes. (Engeström, 1999, p. 35)

A integração de diversos sistemas de atividade nos remete aos ciclos expansivos que projetam o objeto da atividade para a transformação. Essa projeção permite que aconteçam as relaçóes dialéticas entre os sistemas de atividades; a partir daí, 
por meio dos conflitos permeados pela dialogicidade e multivocalidade dos sujeitos envolvidos, provocam as transformaçóes, tanto no objeto da atividade como no próprio sistema de atividade.

Em outras palavras, segundo Daniels (2003, p. 120), para Engeström em seus estudos sobre Teoria da Atividade "a unidade de análise da Teoria da Atividade é a atividade ou prática conjunta”, bem como o processo de transformação social e a natureza conflituosa da prática social. Pretende, portanto, desenvolver ferramentas para compreender os diálogos, as múltiplas perspectivas e redes de sistemas de atividade interativa. Essas redes, permeadas pela dialogicidade e multivocalidade, em que "as contradiçóes e lutas ocorrem na definição do motivo e do objeto da atividade demandam uma análise de poder e controle nos sistemas de atividade em desenvolvimento" (Daniels, 2003, p. 121).

Com base nos conceitos apresentados, é possível perceber que uma discussão crítica e reflexiva realizada pelos participantes do processo ensino-aprendizagem permite a (re)construção dos sentidos e significados atribuídos à educaçáo escolar.

Com base nessas ideias, Daniels e Parrilla (2004, p. 10) apresentam situaçóes nas quais os professores têm procurado sozinhos soluçóes para enfrentar problemas pedagógicos e didáticos complexos, como, por exemplo, a atenção à diversidade. Essas circunstâncias trazem consequências como: dificuldades para solucionar, eles mesmos, o problema; falta de apoio e ajuda; abandono da resolução do problema e da busca criativa de soluçóes e métodos de ensino, preferindo a adoçáo de procedimentos seguros; a vida da sala de aula deixa de responder à diversidade, permitindo a exclusáo do processo ensino-aprendizagem, não só do professor como dos alunos.

Dessa forma, Daniels e Parrilla (2004, p. 17) propõem a criaçáo de Grupos de Apoio entre Professores (GAEPS), com o objetivo de proporcionar aos profissionais da Educação a oportunidade de criar espaços que lhes permitam compartilhar, tratar e resolver problemas imediatos e individuais que surgem na realidade cotidiana de suas salas. No seu exemplo, o grupo colabora na análise e compreensáo de um problema apresentado por um professor e propóem maneiras de intervençáo adequadas às dificuldades identificadas. Assim, é possível atender as necessidades dos professores, bem como as necessidades dos alunos. Daniels e Parrilla (2004, p. 20) enfatizam que essa é uma proposta que procura valorizar as próprias ideias e o conhecimento dos professores que pode ser compartilhado e desenvolvido de maneira eficaz com os colegas de trabalho. Ou seja, quando implantamos mudanças em um determinado segmento da escola, essas mudanças se expandem e possibilitam que os diversos segmentos reconstruam seus sentidos 
e significados socialmente construídos, promovendo novas açóes, transformaçóes e consequentemente novos resultados.

A apropriaçáo dos estudos desses autores serviu de norte para a realizaçáo das experiências apresentadas a seguir.

\section{APRESENTAÇÃO DAS EXPERIÊNCIAS}

Para se compreender como as experiências foram desenvolvidas e analisadas as autoras buscaram em Magalháes (1998) o construto metodológico, por ela denominado pesquisa colaborativa crítica.

(...) é no discurso entre os participantes das trocas discursivas que questóes de seu mundo real [...] sáo questionadas, entendidas e repensadas. Nessas discussōes, um consenso pode ser construído, mas não o é necessariamente e, mesmo que o seja, os conflitos, tensóes, resistências e questôes de poder envolvidas não podem ser escondidos e ignorados, mas problematizados, questionados e trazidos à negociação. (p. 175)

Ainda segundo a autora (2004, p. 60) a prática crítica e reflexiva do professor é permeada por questóes como a compreensáo da escola como um espaço cultural, social e político e náo apenas como um local de transmissão de conhecimentos neutros e desvinculados do contexto particular de açáo e da sociedade mais ampla. Também, a compreensáo da linguagem como espaço para reflexão e negociaçáo.

Em outras palavras, a pesquisa colaborativa crítica dá ênfase à importância da açáo e reflexáo crítica para o repensar de estratégias, baseado na troca de experiências entre os participantes, promovendo a construção de novas formas de pensar e agir, bem como novos conhecimentos que possibilitam a (re)estruturação de açóes por parte dos envolvidos.

Vale lembrar que segundo Magalhães (1998, p. 173), a ênfase na colaboração e reflexão crítica permite aos participantes envolvidos, inclusive ao pesquisador, construírem novos sentidos não só sobre as práticas em situação social de sala de aula, mas também no contexto da escola.

\subsection{Experiência 1}

Iniciei meu trabalho na escola $\mathrm{BC}$, como diretora titular de cargo efetivo, em fevereiro de 2009. A escola estadual BC fica na periferia da cidade de Guarulhos, região metropolitana da cidade de São Paulo, e de acordo com a Fundação Seade 
está entre os grupos 5 e 6 de vulnerabilidade social, nos quais se encontram famílias de baixa renda e no geral jovens com pouca instrução. A escola estava muito desorganizada em relação às questóes administrativas e pedagógicas, embora o prédio tivesse acabado de passar por uma reforma. Os resultados finais de 2008 que refletem os índices do Idesp (Índice de Desenvolvimento da Educaçáo do Estado de São Paulo - Secretaria de Estado da Educação) ${ }^{1}$ estavam muito baixos, em razão das muitas retençóes e de um desempenho baixo no Saresp. Já em 2009 aconteceu uma melhora no desempenho dos alunos no Saresp e na prova Brasil, porém a escola ainda apresentou alto índice de reprovação.

Diante desse quadro, a primeira providência que tomei foi realizar um diagnóstico das necessidades, dificuldades e problemas que apresentavam os mais diversos segmentos da escola, pois não se pode iniciar um movimento buscando qualidade, se não se reconhece que existem problemas. Esse diagnóstico foi realizado na reunião de planejamento do início do ano, na qual, em uma discussáo conjunta - grupo gestor, professores, funcionários e comunidade escolar - foi possível perceber as contradiçóes existentes no discurso dos participantes do processo de ensino-aprendizagem e as práticas desenvolvidas no contexto escolar, em virtude de problemas de relaçóes interpessoais, envolvendo a comunidade - professor, alunos e funcionários.

Também foi possível perceber que os professores e alunos estáo se sentindo excluídos do processo de ensino-aprendizagem, pois, por um lado, o professor está com a sua autoestima muito baixa, em razão do baixo salário, excesso de trabalho (duas ou mais escolas), tem que seguir uma cartilha elaborada pelo governo, o aluno não leva o material e a família náo participa ativamente da vida escolar do filho. Por outro, o aluno apresenta problemas de frequência (que dificulta a continuidade no processo), não leva o material, é desorganizado em relaçăo à sua vida escolar (pois muitas vezes não tem acompanhamento familiar ou vem de uma família desestruturada), o professor não ouve o que ele tem para falar e o acesso ao conhecimento ele obtém por outros meios que náo seja a escola, como internet, celular, televisão. Concluindo:

- o professor não se sente um agente no processo de ensino-aprendizagem;

- o aluno não é protagonista do seu próprio aprendizado;

${ }^{1}$ O Idesp é um indicador que avalia a qualidade da escola. Nessa avaliação, considera-se uma boa escola aquela em que a maior parte dos alunos apreende as competências e habilidades requeridas para a sua série num período de tempo ideal - o ano letivo. Por esse motivo, o Idesp é composto por dois critérios: o desempenho dos alunos nos exames de proficiência do Saresp (quanto aprenderam) e o fluxo escolar (em quanto tempo aprenderam). 
- a comunidade escolar não tem participação ativa e real nos assuntos tratados na escola;

- apesar da informatização, a organização na escrituração de documentos escolares ainda é realizada de forma desorganizada.

A meu ver, o professor encontra-se entre as determinaçóes provindas da legislaçáo vigente e os anseios da comunidade escolar. Muitas vezes, as normas editadas pelo sistema de ensino não preveem um espaço para discussão por parte da escola, provocando no professor um sentimento de incapacidade e que só lhe resta a alternativa de cumprir com o determinado. Dessa forma, e com base no senso comum, não é difícil ouvir os seguintes comentários dos professores: "escola é tudo igual, o professor finge que ensina e o aluno finge que aprende"; "a culpa de fulano de tal não aprender é dos pais que nâo vêm à escola"; "ele está na oitava série e não sabe escrever, a culpa é do professor do ciclo I que não ensinou”.

Também não faz parte da cultura da escola estabelecer espaços de discussáo entre professores e equipe da direçáo e coordenação pedagógica, nos quais aconteça uma reflexão crítica sobre as práticas pedagógicas desenvolvidas em sala de aula. Ou seja, a equipe de profissionais da educaçâao não promove discussóes sobre as normas editadas pelos órgãos públicos, bem como das diversas teorias de ensino-aprendizagem, perpetuando, dessa forma, o ensinar com foco no resultado e não no processo.

Perrenoud (2001), em sua discussão sobre as reformas que devem ser implantadas na educação, argumenta que "[...] é preciso atingir as práticas, a relaçáo pedagógica, o contrato didático, as culturas profissionais, a colaboração entre professores".

Vale lembrar, os princípios apresentados de respeito à diversidade e uma educaçáo de qualidade para todos, explícitos na LDB, na proposta pedagógica da escola e também no Comunicado CENP, de 6-2-2009, que prevê:

Aos Dirigentes Regionais de Ensino, Supervisores de Ensino e Diretores de Escola. A Coordenadoria de Estudos e Normas Pedagógicas, objetivando subsidiar a organizaçáo e o funcionamento das Horas de Trabalho Pedagógico Coletivo - HTPCs solicita das autoridades em epígrafe, especial atençáo às seguintes instruçóes:

1 - A Hora de Trabalho Pedagógico Coletivo - HTPC - caracteriza-se fundamentalmente como:

- espaço de formaçáo continuada dos educadores, propulsor de momentos privilegiados de estudos, discussão e reflexăo do currículo e melhoria da prática docente; 
- trabalho coletivo de caráter estritamente pedagógico, destinado à discussão, acompanhamento e avaliação da proposta pedagógica da escola e do desempenho escolar do aluno. (Sáo Paulo, 2009)

Diante do exposto, essa experiência tem por objetivo proporcionar aos participantes do processo de ensino-aprendizagem, mais especificamente aos professores, condiçōes teóricas e metodológicas que permitam a oportunidade de discussóes sobre as diversas teorias de ensino-aprendizagem e legislaçáo vigente, para promover transformaçóes nas práticas pedagógicas em sala de aula e atender as necessidades da comunidade escolar.

As discussóes aconteceram no HTPC, realizadas duas vezes por semana ao término do período de aulas, com a formação de um grupo de apoio, cujos integrantes são os professores, o professor coordenador pedagógico, o diretor e vice-diretor.

O grupo de apoio realizou discussóes e reflexóes sobre o processo de ensino-aprendizagem divididas em três momentos, quais sejam: a) grupo todo; b) por áreas de conhecimento; c) por disciplinas.

O material utilizado nessas reunióes foi uma apostila elaborada pela diretora da escola e aprovada pelas coordenadoras pedagógicas e vice-diretoras, que trata dos seguintes assuntos:

- apresentação da legislação que criou a unidade escolar;

- calendário escolar;

- horário de HTPC;

- orientaçóes de preenchimento de diário de classe;

- orientaçóes de preenchimento de tarjetas;

- resoluçáo SE 61 - dispóe sobre o rendimento dos alunos;

- deliberação 9/97 - institui o regime de progressão continuada;

- deliberaçáo 11/96 - dispóe sobre pedidos de recursos e reconsideraçóes;

- definição de habilidades e competências;

- matrizes de referência do Saresp;

- matriz de referência do Enem.

Especificamente na escola estadual BC os problemas diagnosticados foram: a desorganização nos registros e os baixos índices de desempenho escolar dos alunos. 
Para tanto, a apostila foi elaborada contemplando os dois itens, pois apresenta uma parte inicial de registros e uma segunda parte relacionada às questôes de desenvolvimento de habilidades e competências em cada área de conhecimento.

Em relaçáo aos primeiros resultados obtidos foi possível perceber:

- uma aceitação geral da apostila e seus conteúdos pelo corpo docente;

- um compromisso por parte do grupo gestor e da coordenaçáo pedagógica em estudar os assuntos tratados, bem como manter a sistematizaçáo e periodicidade das discussóes no HTPC;

- uma melhora significativa no que diz respeito aos registros realizados pelo corpo docente, contendo poucas incorreções;

- uma fluência e coerência nas reunióes de conselho de classe e série ao final do semestre.

Embora tenha havido um avanço na avaliação dos resultados, ainda nos deparamos com alguns professores que não conseguiram se organizar em relaçáo aos registros, e no primeiro semestre, nos dias de jogos da copa do mundo, os trabalhos foram suspensos, bem como ainda há resistência por parte de alguns professores em fazer a reflexão sobre o trabalho da escola.

\subsection{Experiência 2}

Meu trabalho como diretora na escola EP foi gradativamente precisando de um olhar diferenciado e de medidas efetivas, a partir do crescimento do número de alunos e do surgimento de problemas que precisavam ser discutidos com a comunidade escolar, para que todos os seus participantes pudessem assumir responsabilidades na busca de soluçôes e açôes, não só para compreender as situaçóes de violência e indisciplina na escola, mas sobretudo para buscar soluçóes para esses entraves.

Assim, decidi convidar pais, professores e demais funcionários, com a finalidade de formarmos um grupo que se reuniria uma vez por mês para discutir os problemas da escola.

Nesta experiência, relato como decorreram oito reunióes ${ }^{2}$ realizadas em 2008:

\footnotetext{
${ }^{2}$ As reunióes foram gravadas e transcritas para que pudessem servir de estudo e pesquisa para um trabalho de doutorado intitulado "Formaçáo de Grupo de Apoio na Escola: ferramenta para mudanças e transformaçóes nas práticas educacionais", cuja defesa aconteceu em maio de 2010.
} 
Na primeira reuniáo do grupo, estiveram presentes trinta e dois participantes, mas depois desta o grupo ficou restrito a vinte pessoas.

Os objetivos da formaçáo de nosso grupo foram discutidos na primeira reunião e este foi o motivo pelo qual alguns participantes não quiseram continuar frequentando as reunióes subsequentes.

Percebi que alguns pais entenderam que iríamos tratar de assuntos particulares, pertinentes a cada aluno.

Logo de início, notei que alguns participantes se sentiam pouco à vontade para se manifestar e atribuo esse fato à forma como muitas de nossas escolas são estruturadas, apresentando a ideia de que as açôes são propostas de forma vertical, sem que sejam ouvidas as vozes que trazem os anseios dos membros da comunidade escolar.

Esse fato aponta para o que Toseland e Rivas (2005) mostram como valores no trabalho de grupo, a saber:

- a participação e as relaçóes positivas entre pessoas de diferentes credos, raças, idades, naturalidades, nacionalidades e classes sociais;

- o valor da cooperação e da tomada de decisão conjuntas construídas na participação democrática;

- a importância da iniciativa pessoal dentro do grupo;

- a liberdade de participar, expressando pensamentos e sentimentos sobre assuntos que dizem respeito ao grupo, tendo direito de se envolver no processo de tomada de decisóes;

- respeito e dignidade - valorizar e respeitar todos os membros do grupo;

- solidariedade e ajuda mútua;

- valorizar o poder do grupo em ajudar seus membros a se sentirem bem, de tal forma que consigam usar suas habilidades e peculiaridades em favor de fazer a diferença na comunidade escolar;

- camaradagem entre pessoas com diferentes histórias de vida, valorizando as habilidades do grupo em ajudar a enriquecer seus membros, no sentido de fazer com que aprendam uns com outros. O respeito mútuo cresce à medida que as relações se aprofundam na vida do grupo.

No decorrer das reunióes foi se estabelecendo um clima que permitiu aos participantes falarem sobre o que consideravam importante para que transformaçóes na escola pudessem ocorrer. 
O assunto predominante nas primeiras reunióes foi colocar a omissão da família na educação dos alunos como responsável pelos problemas de disciplina e violência da escola.

Assim, os participantes apresentaram ideias para conscientizar os pais da responsabilidade que devem ter no acompanhamento da vida de seus filhos, bem como dos valores que precisam ser cultivados para que a escola possa ser um espaço voltado para o ensino formal.

Alguns se prontificaram a trazer palestrantes para falar com a comunidade escolar sobre assuntos que seriam importantes para alcançar o objetivo do grupo: encontrar soluçóes para nossos problemas com indisciplina e violência no ambiente escolar:

- psicólogos para falar sobre valores, hábitos e atitudes dos alunos;

- pais para apresentar relatos de experiências com seus filhos;

- palestrantes para expor assuntos como valorização da vida;

- educadores com experiências bem-sucedidas em ambientes de extrema violência.

O grupo também organizou um fórum de educação com o tema "Violência e bullying na escola". Esta atividade foi realizada durante um dia, sendo pela manhã uma palestra com uma psicóloga que tem vários trabalhos publicados sobre o tema do fórum e na parte da tarde os participantes puderam escolher oficinas nas quais se envolviam em atividades artísticas e culturais.

Foram organizadas visitas a orfanatos e asilos, para os quais os alunos e membros do grupo levaram doaçóes e também apresentaram cançóes e poemas para alegrar aqueles que são carentes não só de bens materiais, mas também de afeto e calor humano.

O grupo também discutiu a necessidade de se conscientizar os alunos dos cuidados que se deve ter com os espaços coletivos e promoveu campanhas de limpeza e conservaçáo das carteiras da escola.

Apesar da integraçáo dos membros do grupo no decorrer das reuniōes, percebi que muitos pais ainda estáo interessados apenas nos resultados das avaliaçôes. Assim, se as notas não são compatíveis com as expectativas das famílias, nos deparamos com um motivo para que se estabeleça um embate entre alunos, pais e educadores.

Esta situação nos remete a uma visão da educação como um produto. Esse pensamento circula entre nós, fazendo com que nos sintamos peças de um sistema 
neoliberal pelo qual somos movidos num tabuleiro a bel-prazer do objetivo de quem joga o jogo.

Um dos desafios da educação no nosso país, que emergiu das reunióes de nosso grupo, foi questionar o modelo de educação que queremos construir para nossos filhos e para nossos alunos. Devemos também nos questionar que papel cada um de nós representa no processo de ensino e quais são as nossas responsabilidades e como devemos trabalhar com elas.

As transformações nas práticas escolares decorrentes das reuniōes de nosso grupo ainda estão acontecendo lentamente, mas a cultura do Grupo de Apoio se instalou na nossa comunidade escolar de forma definitiva.

Percebemos que o grupo é uma maneira muito assertiva de trabalhar por um ensino que venha ao encontro das necessidades e expectativas da comunidade escolar, de forma que seja ao mesmo tempo democrática e também comprometida com as necessidades da formação cidadá de nossos alunos.

\section{CONSIDERAÇÕES FINAIS}

Este artigo não tem o objetivo de esgotar todas as possibilidades de açóes que permitam a melhoria da qualidade de ensino na educação. Porém, vale ressaltar que a formação de grupos de apoio na escola propicia o acesso dos atores do processo de ensino-aprendizagem às discussóes sobre os mais diversos assuntos que permeiam as práticas pedagógicas desenvolvidas no ambiente escolar.

Vale lembrar que o grupo de apoio aborda um problema que é comum aos que dele participam a partir de um estudo da natureza do problema, identificando suas causas, analisando a informação relativa tanto ao problema como às causas e desenvolvendo soluçóes, por meio do estudo e reflexão da teoria e prática, ou seja, propicia a troca de experiências entre os membros da comunidade escolar.

Ambas as experiências, apesar de terem sido vivenciadas em ambientes que apresentam realidades socioculturais, econômicas e regionais diferenciadas, demonstram que os problemas diagnosticados são semelhantes, bem como os sentidos e significados atribuídos à educaçáo escolar. Em outras palavras, embora os grupos de apoio tenham sua constituição diferente, foram abordados assuntos como violência escolar, indisciplina, organização no registro de dados, papel social da escola, da família e do professor em sala de aula e as relaçóes interpessoais entre os membros da comunidade escolar. 
As experiências denotam a importância de que se promovam mudanças e transformações não só na legislação, mas também na cultura escolar desenvolvida nas diversas comunidades de prática, que está arraigada em conceitos e preceitos que de há muito não atendem a diversidade das necessidades da sociedade.

\section{REFERÊNCIAS BIBLIOGRÁFICAS}

BRASIL. Lei no 9394, de 20 de dezembro de 1996. Estabelece as diretrizes e bases da educação nacional. Diário Oficial [da] República Federativa do Brasil, Brasília, 23 de dezembro de 1996. Seção 1, p. 27833-41.

BRASIL. Senado Federal. Constituição da República Federativa do Brasil, de 5 de outubro de 1988. Brasília, DF: Senado Federal, 1988, 292 p.

DANIELS, H. Vygotsky e a pedagogia. São Paulo: Loyola, 2003, $246 \mathrm{p}$.

DANIELS, H.; PARRILLA, A. Criação $e$ desenvolvimento de grupos de apoio entre professores. São Paulo: Loyola, 2004, 220 p.

ENGESTRÖM, Y. Activity theory and individual and social transformation. In: ENGESTRÖM, Y.; MIETTINEN, R.; PUNAMÄKI, R. Perspectives on activity theory. 3. ed. New York: Cambridge University, 1999. p. 19-38.

MAGALHÃES, M. C. C. A Linguagem na formação de professores reflexivos e críticos. In: - (Org.). A Formação do professor como um profissional crítico. São Paulo: Mercado das Letras, 2004. p. 59-85.

Projetos de formação contínua de educadores para uma prática crítica. The Especialist, São Paulo, v. 19, n. 2, p. 169-184, 1998.

MAGALHÃES, M. C. C. et al. Educando para a cidadania em contextos de transformações. Revista The Specialist. São Paulo, v. 27, p.

169-188, 2006.

PERRENOUD, P. A Pedagogia na escola das diferenças: fragmentos de uma sociologia do fracasso. Porto Alegre: Artmed, 2001. $230 \mathrm{p}$.

SÃO PAULO (Estado). Fundação Seade. Indice Paulista de Vulnerabilidade Social. Disponível em: <http://www.seade.gov.br/projetos/ipvs/>. Acesso em: 12 mar. 2009.

SÃO PAULO (Estado). Secretaria da Educação. Comunicado CENP de 06 de fevereiro de 2009. Diário Oficial do Estado de São Paulo, São Paulo, 7 de fevereiro de 2009, Seção I, p. 119.

Programa de qualidade da escola.

Disponível em: <http://idesp.edunet.sp.gov. br>. Acesso em: 12 mar. 2009.

TOSELAND, R. W.; RIVAS, R. F. An Introduction to group work practice. Boston: Person Education. Inc., 2005.

VIGOTSKY, L. S. A Construção do pensamento e da linguagem. São Paulo: Martins Fontes, 19202001. $496 \mathrm{p}$.

A Formação social da mente: o desenvolvimento dos processos psicológicos superiores. In: COLE, M.; JOHN-STEINER, V.; SCRIBNER, S.; SOUBERMAN, E. (Org). Tradução de José Cipolla Neto, Luis Silveira Menna Barreto, Solange Castro Afeche. 6. ed. São Paulo: Martins Fontes, 1930/2002. 191 p.

Recebido em: janeiro 2011

Aprovado para publicação em: maio 2011 